Cite this: Chem. Commun., 2012, 48, 4821-4823

\section{Trifluoromethyl acting as stopper in [2]rotaxane $\dagger$}

\author{
Suvankar Dasgupta, ${ }^{a}$ Kuo-Wei Huang ${ }^{b}$ and Jishan $\mathrm{Wu}^{* a}$ \\ Received 11th February 2012, Accepted 23rd March 2012 \\ DOI: $10.1039 / \mathrm{c} 2 \mathrm{cc} 31009 \mathrm{k}$
}

A modified dumbbell obtained by replacing one of the phenyl groups of the dibenzylammonium with a strong electronwithdrawing trifluoromethyl group templated the synthesis of the smallest [2]rotaxane reported so far. The trifluoromethyl group not only enhances the templating effect of the dumbbell but also acts as the stopper to prevent dethreading of a [20]crown ether macrocycle.

Mechanically interlocked molecules $(\mathrm{MIM})^{1}$ in addition to being aesthetically appealing, also find potential applications in molecular nanotechnology. For example, rotaxane ${ }^{2}$ based molecular switches ${ }^{3}$ have been visioned as potential candidates for molecular scale electronics, ${ }^{4}$ molecular actuators, ${ }^{5}$ molecular elevators, ${ }^{6}$ smart surfaces $^{7}$ and controlled drug release. ${ }^{8}$ For constructing rotaxanes, the template-directed clipping ${ }^{9}$ methodology involves self-assembly of acyclic precursors around the recognition site of the dumbbell followed by reversible condensation ${ }^{9 a, b, d_{f}, h}$ or metathesis ${ }^{9 c, e, g, i}$ to generate the macrocycle encompassing the recognition site. The ring closing metathesis (RCM) of an acyclic diolefin polyether, in the presence of the "dumbbell" $\left(\mathrm{ArCH}_{2}\right)_{2} \mathrm{NH}_{2}{ }^{+}(\mathrm{Ar}=$ aryl $)$, is known to produce interlocked structures containing [24] crown ether. ${ }^{9 b-d}$

Very recently, using RCM we obtained a series of [2]rotaxanes on dibenzylammonium dumbbell (1, Fig. 1) with smaller macrocycles such as [20], [21] and [22]crown ethers, by systematically varying the alkyl chain length of the acyclic diolefin polyether. ${ }^{10}$ Inspired by the success with dibenzylammonium dumbbell and knowing that [21]crown ether was the smallest crown ether to be threaded by dialkylammonium ion (2, Fig. 1), ${ }^{11}$ one can contemplate that clipping a [20]crown ether onto a dialkylammonium ion will give a [2] rotaxane with alkyl groups acting as stoppers! Therefore, salt $\mathbf{2} \cdot \mathbf{P F}_{\mathbf{6}}{ }^{12}$ and acyclic diolefin polyether $\mathbf{5}$ were prepared. ${ }^{10} \mathrm{~A}$ mixture of two equivalents of $\mathbf{5}$ with one equivalent of $\mathbf{2} \cdot \mathbf{P F}_{\mathbf{6}}$ was stirred in $\mathrm{CHCl}_{3}-\mathrm{CH}_{3} \mathrm{CN}(3: 1)$ for $24 \mathrm{~h}$, followed by removing the solvent under reduced pressure

\footnotetext{
${ }^{a}$ Department of Chemistry, National University of Singapore, 3 Science Drive 3, Singapore 117543.E-mail: chmwuj@nus.edu.sg; Fax: (+65) 6779 1691; Tel: (+65) 65162677

${ }^{b}$ King Abdullah University of Science and Technology (KAUST), Division of Chemical and Life Sciences and Engineering and KAUST Catalysis Center, Thuwal 23955-6900, Saudi Arabia

$\dagger$ Electronic supplementary information (ESI) available: Synthetic procedures, nominal ESI-MS and HR ESI-MS spectra, 2D NOESY spectrum, stacked ${ }^{1} \mathrm{H}$ NMR spectra, decay curve, ${ }^{1} \mathrm{H},{ }^{13} \mathrm{C}$ and ${ }^{19} \mathrm{~F}$ NMR spectra. See DOI: $10.1039 / \mathrm{c} 2 \mathrm{cc} 31009 \mathrm{k}$
}



Fig. 1 Molecular structures of the dumbbells 1-4, acyclic diolefin polyether 5, and [20]crown ether $\mathbf{6}$.

without heating. The residue, expected to be the complex 7. $\mathbf{P F}_{6}$ (soluble in $\mathrm{CH}_{2} \mathrm{Cl}_{2}$ ), was subjected to $\mathrm{RCM}$ with Grubbs' 2nd generation catalyst under refluxing conditions in dry DCM for $60 \mathrm{~h}$ (Scheme 1).

Although the peak corresponding to the desired compound 10. PF $_{6}$ was detected in nominal ESI-MS (Fig. S1, ESI $\dagger$ ), purification by column chromatography failed to isolate 10. $\mathbf{P F}_{6}$. Dethreading during purification may explain this finding if $\mathbf{1 0} \cdot \mathbf{P F}_{\mathbf{6}}$ is a pseudorotaxane. However, no threading

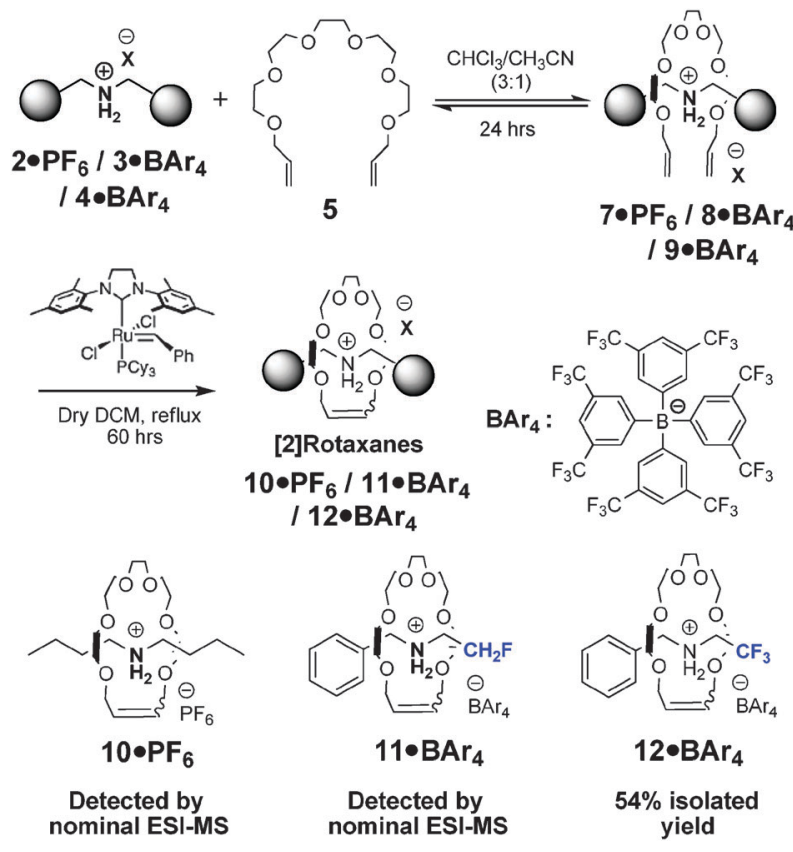

Scheme 1 RCM of dumbbells $\mathbf{2} \cdot \mathbf{P F}_{6}, \mathbf{3} \cdot \mathbf{B A r}_{4}$ and $\mathbf{4} \cdot \mathbf{B A r}_{\mathbf{4}}$. 

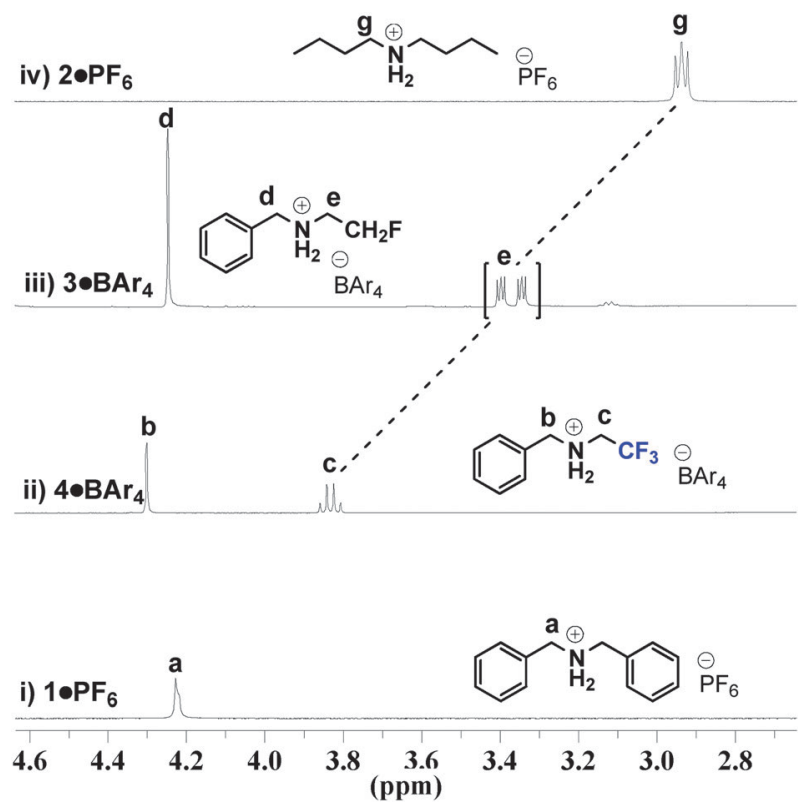

Fig. 2 Partial ${ }^{1} \mathrm{H}$ NMR spectra $\left(500 \mathrm{MHz}, \mathrm{CD}_{3} \mathrm{CN}\right)$, displaying the increase in acidity of methylene protons $\mathbf{g} \rightarrow \mathbf{e} \rightarrow \mathbf{c}$ in dumbbells $\mathbf{2} \rightarrow \mathbf{3} \rightarrow \mathbf{4}$. Benzylic protons $\mathbf{a}$ in $\mathbf{1}$ is for reference.

could be detected by ${ }^{1} \mathrm{H}$ NMR on refluxing a mixture of $\mathbf{2} \cdot \mathbf{P F}_{\mathbf{6}}$ with three equivalents ${ }^{13}$ of [20]crown ether 6 (for synthesis, see $\mathrm{ESI} \dagger$ ) for 7 days in $\mathrm{CH}_{2} \mathrm{Cl}_{2}$ followed by another 7 days in $\mathrm{CHCl}_{3} \cdot \mathbf{1 0} \cdot \mathbf{P F}_{\mathbf{6}}$ was expected to be formed in extremely low yield (if at all), which would make it difficult to be isolated. This may be ascribed to the weaker templating effect of the dumbbell 2 than 1 due to the lower acidity of $-\mathrm{CH}_{2} \mathrm{NH}_{2}{ }^{+} \mathrm{CH}_{2}-$ protons (responsible for templating effect) in $\mathbf{2}$ (protons $\mathbf{g}$ $\sim 2.9$ ppm, Fig. 2(iv)) compared to 1 (protons a $\sim 4.2 \mathrm{ppm}$, Fig. 2(i)). To increase the templating effect of the dumbbell, $N$-benzylalkylammonium dumbbells $\mathbf{3}$ and $\mathbf{4}$ having electronwithdrawing fluoromethyl $\left(-\mathrm{CH}_{2} \mathrm{~F}\right)$ and trifluoromethyl $\left(-\mathrm{CF}_{3}\right)$ stopper groups were prepared. However, the dumbbell with difluoromethyl $\left(-\mathrm{CHF}_{2}\right)$ stopper group could not be synthesized since the precursors $\mathrm{F}_{2} \mathrm{CHCH}_{2} \mathrm{NH}_{2}$ or $\mathrm{F}_{2} \mathrm{CHCHO}$ was not easily available.

The electronic impact of $-\mathrm{CH}_{2} \mathrm{~F}$ and $-\mathrm{CF}_{3}$ stopper groups can be observed from the downfield chemical shifts of the protons e ( $\sim 3.4$ ppm, Fig. 2(iii)) and $\mathbf{c}(\sim 3.9$ ppm, Fig. 2(ii)) in $\mathbf{3}$ and $\mathbf{4}$, respectively. The dumbbells $\mathbf{3}$ and $\mathbf{4}$ were prepared with $\mathrm{BAr}_{4}$ counter ion because their chloride precursors (15.Cl and 16. Cl, see ESI $\dagger$ ) could not be dissolved even in hot water and thus could not undergo a clean counter ion exchange reaction by mixing with aqueous $\mathrm{NH}_{4} \mathrm{PF}_{6}$. Moreover, the $\mathrm{BAr}_{4}$ counter ion is a weakly associating ion and extremely lipophilic, making 3 and $\mathbf{4}$ easily dissolve in DCM. ${ }^{14}$ The salts $\mathbf{3}$. $\mathbf{B A r}_{4}$ and $\mathbf{4} \cdot \mathbf{B A r}_{4}$ were then mixed with two equivalents of $\mathbf{5}$ to afford $\mathbf{8} \cdot \mathbf{B A r}_{\mathbf{4}}$ and $\mathbf{9} \cdot \mathbf{B A r}_{\mathbf{4}}$, respectively, which as for $\mathbf{7} \cdot \mathbf{P F}_{\mathbf{6}}$ above, were subjected to RCM with the Grubbs' 2nd generation catalyst under refluxing condition in dry DCM for $60 \mathrm{~h}$.

The [2] rotaxane 11. $\mathbf{B A r}_{4}$, corresponding to the salt $\mathbf{3} \cdot \mathbf{B A r}_{4}$, could only be detected in nominal ESI-MS (Fig. S2, ESI $\dagger$ ) while [2] rotaxane $\mathbf{1 2} \cdot \mathbf{B A r}_{\mathbf{4}}$ obtained from salt $\mathbf{4} \cdot \mathbf{B A r}_{\mathbf{4}}$ was isolated as a white solid in reasonably good yield $(54 \%$, Scheme 1), reflecting the strong templating effect of $\mathbf{4} \cdot \mathbf{B A r}_{\mathbf{4}}$.

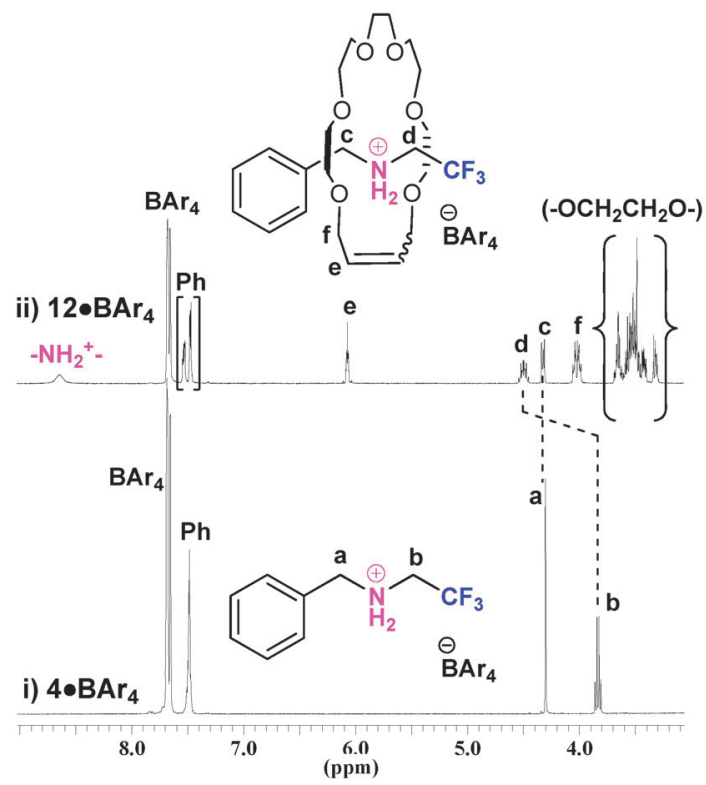

Fig. $3{ }^{1} \mathrm{H}$ NMR spectra $\left(500 \mathrm{MHz}, \mathrm{CD}_{3} \mathrm{CN}\right)$ of (i) $\mathbf{4} \cdot \mathbf{B A r}_{4}$, and (ii) 12. $\mathbf{B A r} \mathbf{r}_{\mathbf{4}}$. Dotted lines indicate the downfield shift observed (b $\rightarrow$ d) due to the effect of H-bonding interaction.

The ${ }^{1} \mathrm{H}$ NMR spectrum of [2] rotaxane 12.BAr $\mathbf{r}_{4}$ (Fig. 3(ii)), displaying an $-\mathrm{NH}_{2}{ }^{+}-$hump $(\sim 8.6 \mathrm{ppm})$, olefinic proton peak (protons e $\sim 6.1 \mathrm{ppm}$ ), and splitting of benzylic protons (protons $\mathbf{c} \sim 4.3 \mathrm{ppm}$ ), clearly indicated a [2]rotaxane structure encircled with a [20]crown ether. ${ }^{10}$ The large downfield shift of the methylene protons $\mathbf{b}$ in $\mathbf{4} \cdot \mathbf{B A r}_{\mathbf{4}}$ to $\mathbf{d}$ in $\mathbf{1 2} \cdot \mathbf{B A r}_{\mathbf{4}}$ can be explained by the participation of protons $\mathbf{d}$ in hydrogen bonding with the oxygen atoms of the [20]crown ether, substantiating an interlocked geometry for [2] rotaxane 12.BAr 4 . The observed HR ESI-MS result for 12. $\mathbf{B A r} \mathbf{r}_{\mathbf{4}}$ showed a peak at 480.2573 (Fig. S3, ESI $\dagger$ ) with $-1.2 \mathrm{ppm}$ deviation from the calculated HRMS (480.2567) for $\left[\mathrm{M}-\mathrm{BAr}_{4}\right]^{+}$, showing that pure $\mathbf{1 2} \cdot \mathbf{B A r}_{4}$ can be obtained by column chromatography. Repeated attempts to grow suitable single crystals failed, consequently 2D NOESY NMR (Fig. S4, ESI $\dagger$ ) was performed in $\mathrm{CDCl}_{3}$ to reveal the interlocked structure.

To ascertain the kinetic stability of $\mathbf{1 2} \cdot \mathbf{B A r}_{\mathbf{4}}$, its ${ }^{1} \mathrm{H}$ NMR spectrum was recorded in DMSO- $\mathrm{d}_{6}$, and a tiny peak $(\sim 5.75 \mathrm{ppm}$, Fig. S5(ii), ESI $\dagger$ ) corresponding to the free crown ether was observed. We became suspicious of dethreading, however a threading experiment performed with the salt $\mathbf{4} \cdot \mathbf{B A r}_{\mathbf{4}}$ and three equivalents of [20]crown ether $\mathbf{6}$ failed despite refluxing the mixture in $\mathrm{CH}_{2} \mathrm{Cl}_{2}$ for 7 days followed by another 7 days in $\mathrm{CHCl}_{3}$. Moreover, in the ${ }^{1} \mathrm{H}$ NMR spectrum of $\mathbf{1 2} \cdot \mathbf{B A r}_{4}$ recorded in DMSO-d $\mathrm{d}_{6}$ (Fig. S5, ESI $\dagger$ ), the absence of peak corresponding to the free dumbbell suggested decay of [2]rotaxane 12. $\mathbf{B A r}_{4}$ was not by dethreading. Some electronic effects, operative in the component $-\mathrm{NH}_{2}{ }^{+} \mathrm{CH}_{2} \mathrm{CF}_{3}$ of $\mathbf{1 2} \cdot \mathbf{B A r}_{4}$, may be responsible for the slow decomposition in polar solvent (DMSO). A time-based concentration study of $\mathbf{1 2} \cdot \mathbf{B A r}_{\mathbf{4}}$ in ${ }^{D M S O}-\mathrm{d}_{6}$ over a week suggested a first-order decay with half-life of $26.1 \mathrm{~h}$ (Fig. S6, ESI $\dagger$ ). However, the compound 12. $\mathbf{B A r}_{4}$ did not show any decomposition after standing in $\mathrm{CDCl}_{3}$ over two weeks and no dethreading was observed on heating up to $373 \mathrm{~K}$ in $\mathrm{C}_{2} \mathrm{D}_{2} \mathrm{Cl}_{4}$ (Fig. S7, ESI + ). 

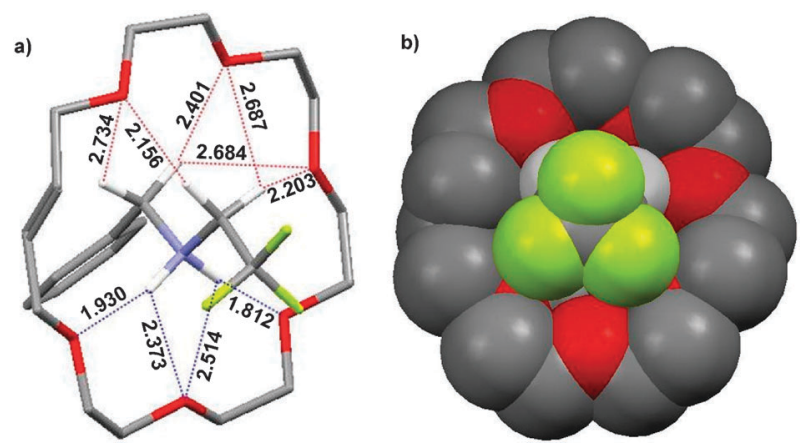

Fig. 4 Capped stick (a) and space-filling (b) representation for the calculated structure of [2]rotaxane 12. $\mathbf{B A r}_{4}$, showing short contact distances (in $\AA$ ). (a) In capped stick structures, [C-H...O] and $[\mathrm{N}-\mathrm{H} \cdots \mathrm{O}]$ distances are shown. Hydrogen atoms not involved in short contact distances are omitted for clarity. (b) In space-filling representation, oxygen atoms of crown ether and fluorine atoms of the dumbbell are represented in red and yellow, respectively. All the hydrogen atoms are omitted for clarity.

Theoretical calculations at the B3LYP/6-31+G(d,p) level of theory were conducted to understand the geometry of the [2]rotaxane 12 cation. ${ }^{15}$ This method was validated by comparing the optimized structure of an analogous [2] rotaxane with dibenzylammonium dumbbell interlocked with a [20]crown ether ${ }^{10}$ with its crystallographic structure, and it was confirmed that the computed geometry was in good agreement with the experimental observation. Similar calculations on cation $\mathbf{1 2}$ predict an interlocked [2] rotaxane structure involving multiple $[\mathrm{C}-\mathrm{H} \cdots \mathrm{O}]$ and $[\mathrm{N}-\mathrm{H} \cdots \mathrm{O}]$ interactions (Fig. 4a). The spacefilling representation (Fig. 4b) gives an estimate of the cavity size of the [20]crown ether being smaller than the volume of the $\mathrm{CF}_{3}$ group, which is consistent with the experimental results confirming the role of the $\mathrm{CF}_{3}$ moiety as a stopper for the [20]crown ether.

In conclusion, the potential of alkyl or fluorinated alkyl groups acting as stoppers has been studied in detail, with the [20]crown ether as the encircling macrocycle. RCM has been utilized to clip the macrocycle onto the dumbbell. Indeed, we have obtained a very strongly interlocked [2] rotaxane on the $\mathrm{PhCH}_{2} \mathrm{NH}_{2}{ }^{+} \mathrm{CH}_{2} \mathrm{CF}_{3}$ dumbbell encircled with a [20]crown ether, highlighting the role of trifluoromethyl group in enhancing the template effect (needed for clipping) along with acting as a stopper. The [2]rotaxane 12. $\mathbf{B A r}_{\mathbf{4}}$, though not stable in polar solvents, remains extremely stable in chlorinated solvents even at $373 \mathrm{~K}$, underlying the steric resistance offered by the trifluoromethyl group is sufficient for acting as a stopper, which is also supported by theoretical calculations. The [2] rotaxane 12. $\mathbf{B A r}_{4}$ represents the smallest [2]rotaxane reported so far, in terms of the molar mass and the total number of the atoms for the cationic part. ${ }^{16}$

This work was financially supported by the NUS AcRF Tier 1 grant (R-143-000-467-112) and KAUST. We thank Han Yanhui and Ong Wei Qiang for 2D NMR analysis.

\section{Notes and references}

1 (a) D. B. Amabilino and J. F. Stoddart, Chem. Rev., 1995, 95, 2725-2828; (b) J. F. Stoddart, Chem. Soc. Rev., 2009, 38, 1802-1820; (c) J. E. Beves, B. A. Blight, C. J. Campbell,
D. A. Leigh and R. T. McBurney, Angew. Chem., Int. Ed., 2011, 50, 9260-9327.

2 (a) I. T. Harrison and S. Harrison, J. Am. Chem. Soc., 1967, 89, 5723-5724; (b) G. Schill, W. Beckmann and W. Vetter, Angew. Chem., Int. Ed. Engl., 1973, 12, 665-666; (c) C. A. Schalley, K. Beizai and F. Vögtle, Acc. Chem. Res., 2001, 34, 465-476; (d) A. Harada, A. Hashidzume, H. Yamaguchi and Y. Takashima, Chem. Rev., 2009, 109, 5974-6023; (e) H. Lahlali, K. Jobe, M. Watkinson and S. M. Goldup, Angew. Chem., Int. Ed., 2011, 50, 4151-4155.

3 (a) B. L. Feringa, Acc. Chem. Res., 2001, 34, 504-513; (b) R. Klajn, J. F. Stoddart and B. A. Grzybowski, Chem. Soc. Rev., 2010, 39, 2203-2237; (c) H. Li, A. C. Fahrenbach, A. Coskun, Z. Zhu, G. Barin, Y. L. Zhao, Y. Y. Botros, J. P. Sauvage and J. F. Stoddart, Angew. Chem., Int. Ed., 2011, 50, 6782-6788.

4 (a) C. P. Collier, G. Mattersteig, E. W. Wong, Y. Luo, K. Beverly, J. Sampaio, F. M. Raymo, J. F. Stoddart and J. R. Heath, Science, 2000, 289, 1172-1175; (b) J. E. Green, J. W. Choi, A. Boukai, Y. Bunimovich, E. Johnston-Halperin, E. DeIonno, Y. Luo, B. A. Sheriff, K. Xu, Y. S. Shin, H. R. Tseng, J. F. Stoddart and J. R. Heath, Nature, 2007, 445, 414-417.

5 (a) M. C. Jimenez, C. Dietrich-Buchecker and J. P. Sauvage, Angew. Chem., Int. Ed., 2000, 39, 3284-3287; (b) Y. Liu, A. H. Flood, P. A. Bonvallet, S. A. Vignon, B. H. Northrop, H. R. Tseng, J. O. Jeppesen, T. J. Huang, B. Brough, M. Baller, S. Magonov, S. D. Solares, W. A. Goddard, C. M. Ho and J. F. Stoddart, J. Am. Chem. Soc., 2005, 127, 9745-9759; (c) J. Wu, K. C. Leung, D. Benitez, J. Y. Han, S. J. Cantrill, L. Fang and J. F. Stoddart, Angew. Chem., Int. Ed., 2008, 47, 7470-7474.

6 (a) J. D. Badjic, V. Balzani, A. Credi, S. Silvi and J. F. Stoddart, Science, 2004, 303, 1845-1849; (b) J. D. Badjic, C. M. Ronconi, J. F. Stoddart, V. Balzani, S. Silvi and A. Credi, J. Am. Chem. Soc., 2006, 128, 1489-1499.

7 J. Berna, D. A. Leigh, M. Lubomska, S. M. Mendoza, E. M. Perez, P. Rudolf, G. Teobaldi and F. Zerbetto, Nat. Mater., 2005, 4, 704-710.

8 (a) T. D. Nguyen, H. R. Tseng, P. C. Celestre, A. H. Flood, Y. Liu, J. F. Stoddart and J. I. Zink, Proc. Natl. Acad. Sci. U. S. A., 2005, 102, 10029-10034; (b) S. Saha, K. C. F. Leung, T. D. Nguyen, J. F. Stoddart and J. I. Zink, Adv. Funct. Mater., 2007, 17, 685-693.

9 (a) W. Clegg, C. Gimenez-Saiz, D. A. Leigh, A. Murphy, A. M. Z. Slawin and S. J. Teat, J. Am. Chem. Soc., 1999, 121, 4124-4129; (b) P. T. Glink, A. I. Oliva, J. F. Stoddart, A. J. P. White and D. J. Williams, Angew. Chem., Int. Ed., 2001, 40, 1870-1875; (c) A. F. Kilbinger, S. J. Cantrill, A. W. Waltman, M. W. Day and R. H. Grubbs, Angew. Chem., Int. Ed., 2003, 42, 3281-3285; (d) J. Wu, K. C. Leung and J. F. Stoddart, Proc. Natl. Acad. Sci. U. S. A., 2007, 104, 17266-17271; (e) P. G. Clark, E. N. Guidry, W. Y. Chan, W. E. Steinmetz and R. H. Grubbs, J. Am. Chem Soc., 2010, 132, 3405-3412; $(f)$ M. E. Belowich, C. Valente and J. F. Stoddart, Angew. Chem., Int. Ed., 2010, 49, 7208-7212; (g) A. M. Fuller, D. A. Leigh and P. J. Lusby, J. Am. Chem. Soc., 2010, 132, 4954-4959; (h) D. M. D'Souza, D. A. Leigh, L. Mottier, K. M. Mullen, F. Paolucci, S. J. Teat and S. Zhang, J. Am. Chem. Soc., 2010, 132, 9465-9470; (i) N. Momcilovic, P. G. Clark, A. J. Boydston and R. H. Grubbs, J. Am. Chem. Soc., 2011, 133, 19087-19089.

10 S. Dasgupta and J. Wu, Chem. Sci., 2012, 3, 425-432.

11 C. Zhang, S. Li, J. Zhang, K. Zhu, N. Li and F. Huang, Org. Lett., 2007, 9, 5553-5556.

12 P. R. Ashton, P. J. Campbell, E. J. T. Chrystal, P. T. Glink, S. Menzer, D. Philp, N. Spencer, J. F. Stoddart, P. A. Tasker and D. J. Williams, Angew. Chem., Int. Ed. Engl., 1995, 34, 1865-1869.

13 P. R. Ashton, I. Baxter, M. C. T. Fyfe, F. M. Raymo, N. Spencer, J. F. Stoddart, A. J. P. White and D. J. Williams, J. Am. Chem. Soc., 1998, 120, 2297-2307.

14 B. A. Blight, A. Camara-Campos, S. Djurdjevic, M. Kaller, D. A. Leigh, F. M. McMillan, H. McNab and A. M. Slawin, J. Am. Chem. Soc., 2009, 131, 14116-14122.

$15 \mathrm{See} \mathrm{ESI} \dagger$ for computational details.

16 (a) C. C. Hsu, N. C. Chen, C. C. Lai, Y. H. Liu, S. M. Peng and S. H. Chiu, Angew. Chem., Int. Ed., 2008, 47, 7475-7478; (b) H. Lahlali, K. Jobe, M. Watkinson and S. M. Goldup, Angew. Chem., Int. Ed., 2011, 50, 4151-4155. 